\title{
Recent Measurements of Electrical Conductivity and Ion Pair Production Rate, and the Ion-Ion Recombination Coefficient Derived from Them in the Lower Stratosphere
}

\author{
Yasuhiro MORITA \\ Research Institute of Atmospherics, Nagoya University, \\ Toyokawa, Aichi 442, Japan \\ (Received August 20, 1982; Revised February 2, 1983)
}

\begin{abstract}
The results of balloon measurements of electrical conductivity and ion pair production rate obtained from the Atmospheric Electrical Measurements Workshop at the University of Wyoming in the summer of 1978 are presented. Reasonable agreement was obtained from the comparison flights of electrical conductivity. The small difference in the comparative measurements of ion pair production rate was found at stratospheric heights. The profiles of ion pair production rate measured during the period of different sunspot numbers showed a marked dependence of ion pair production rate on solar activity. The height variation of the effective ion-ion recombination coefficient calculated from the measured ion pair production rate and positive polar conductivity agrees reasonably well with the presently accepted theoretical concepts. The crossover from three-body to two-body recombination occurs at an altitude of around $23 \mathrm{~km}$.
\end{abstract}

\section{Introduction}

Among many parameters of Atmospheric Electricity, the electrical conductivity and ion pair production rate are the most fundamental parameters to understand the electrical state of the atmosphere from the ground to the stratosphere. Many measurements of these parameters up to stratospheric heights have been made in recent years (e.g., NeHER, 1971; ANDERSON, 1973; HAKE et al., 1973; MORITA and IsHIKAWA, 1976; MoRITA et al., 1979; and others). To understand the complex dependence of the electrical state of the atmosphere on the height, systematic measurements of these parameters have to be carried out at different geomagnetic latitudes and solar conditions. For this reason several balloon measurements of electrical parameters have been made over Sanriku, Iwate (Japan), Laramie, Wyoming and Hilo, Hawaii (USA) as a part of Japan-USA cooperative sounding program in recent years (MORITA and ISHIKAWA, 1976; and MORITA et al., 1979). More recently, Atmospheric Electrical Measurements Workshop was held at the University of Wyoming in the summer of 1978. The outline and results of workshop are presented in 
detail by Rosen et al. (1982). This paper presents some of the results of electrical conductivity and ion pair production rate obtained from the workshop. The profile of the effective ion-ion recombination coefficient calculated from the measured ion pair production rate and positive polar conductivity is also presented.

\section{Measurements}

The Atmospheric Electrical Measurements Workshop was made to compare several instruments measuring the electrical parameters through the effort of the Atmospheric Physics group of the University of Wyoming. The simultaneous measurements of electrical conductivity were made on two balloon flights during the workshop. On the first flight the electrical conductivity was measured by three universities of Wyoming (Rosen and Hofmann), Tübingen (Gringel) and Nagoya (Morita). The measurement of ion pair production rate of Nagoya University (Morita) was also made on this flight (W-183: the serial number of balloon flight of the University of Wyoming). On the second flight (W-186) two conductivity instruments of Gringel and Morita were compared. The balloon flights were conducted on July 30 (W-183) and on Aug. 4 (W-186), 1978. The positive polar conductivity was measured by balloon-borne small Gerdien type condensers. The condensers used in the present measurements are believed to be suitable at higher altitudes where high mobility ions predominated. On July 30 another conductivity profile was measured by Kyoto University (Ogawa) using the relaxation method (OGAwA, 1973).

The vertical profiles of ion pair production rate were measured simultaneously by the University of Wyoming (Hofmann and Rosen) and Nagoya University (Morita). The balloon flight was also conducted on Aug. 4, 1978 (W-188). The ionization chamber used by Nagoya University consisted of a sealed alminium sphere containing clean and dry aged air at ground pressure. The wall thickness is $0.8 \mathrm{~mm}$, and the energy absorbed by the wall is $13.5 \mathrm{MeV}$ for protons and $0.77 \mathrm{MeV}$ for electrons. The chamber was originally designed and constructed by IKEBE (1970). The University of Wyoming used a large, non-sealed and very thin walled ionization chamber (HoFMANN and RosEN, 1979). The chamber was open to the outside atmosphere and the inside air was at ambient pressure. The walls of the chamber are believed to be sufficiently thin to allow all soft component of the cosmic rays and to avoid interactions of high energy cosmic rays in the wall at high altitude.

\section{Results and Discussions}

\subsection{Comparative measurements of electrical conductivity and ion pair production rate}

Figure 1 shows the profiles of positive polar conductivity measured simultaneously during the flight W-183. Open and closed circles in Fig. 1 give the measurements of Gringel, and Rosen and Hofmann, respectively, while the continuous line shows the results of Morita. Gringel and Morita used the Gerdien condensers of 


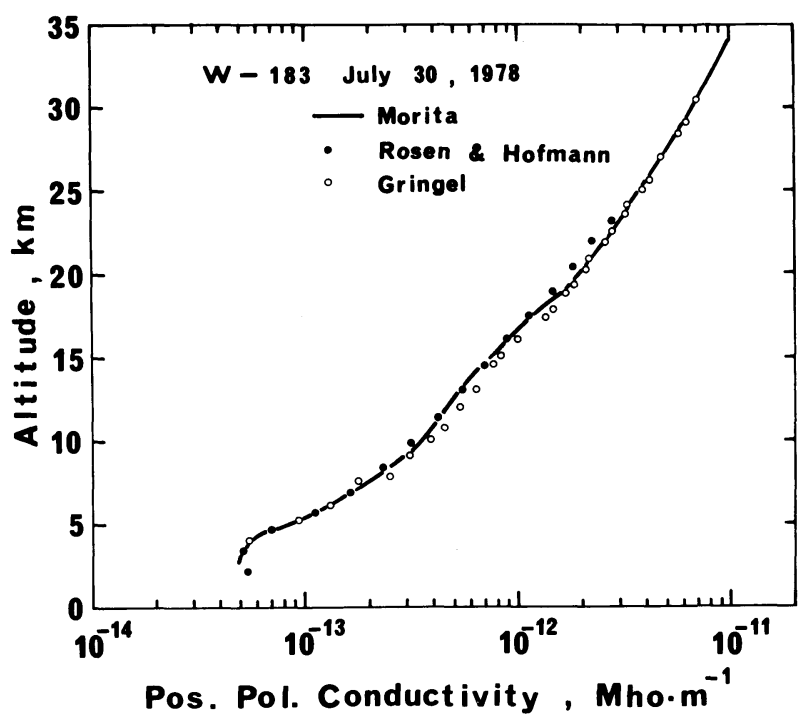

Fig. 1. A comparison of positive polar conductivity profiles over Laramie, Wyoming on July 30, 1978.

nearly the same geometry and very similar design. On the other hand, the condenser used by Rosen and Hofmann was of considerably different geometry and design from the others. Thus the results of Gringel and Morita would be expected to be consistent as is found in Fig. 1. However, the results of Rosen and Hofmann seem also to agree reasonably well with the others. The agreement was also observed in the second set of simultaneous conductivity measurements between Gringel and Morita. The conductivity profile measured by Ogawa seems to be different and of lower absolute values. The discrepancy may be attributed to the difference of the method of conductivity measurements.

The results of the comparison flight to measure ion pair production rate are shown in Fig. 2. The profiles are shown by normalizing the ion pair production rates to the standard temperature and pressure (STP ionization). It is evident from Fig. 2 that the agreement between the two profiles is reasonably good in the limited altitude region from 10 to $15 \mathrm{~km}$. The discrepancies between the two profiles are significant both above and below this altitude range, especially above $20 \mathrm{~km}$. A larger ion pair production rate obtained with the thin walled ionization chamber of the University of Wyoming below about $5 \mathrm{~km}$ shows that the ionization chamber has a response to low energy radiation. Between 5 and $10 \mathrm{~km}$ altitude the electrometer of the ionization chamber of the University of Wyoming developed an anomalous behavior, thus the results should not be rigorously compared in this region (ROSEN et al., 1982). After the workshop additional comparative measurements of the same instruments were made on Dec. 19, 1979. The results of comparison flights suggest that the agreement is quite good in the altitudes between 5 and $15 \mathrm{~km}$ and small differences are evident at higher altitudes. No 


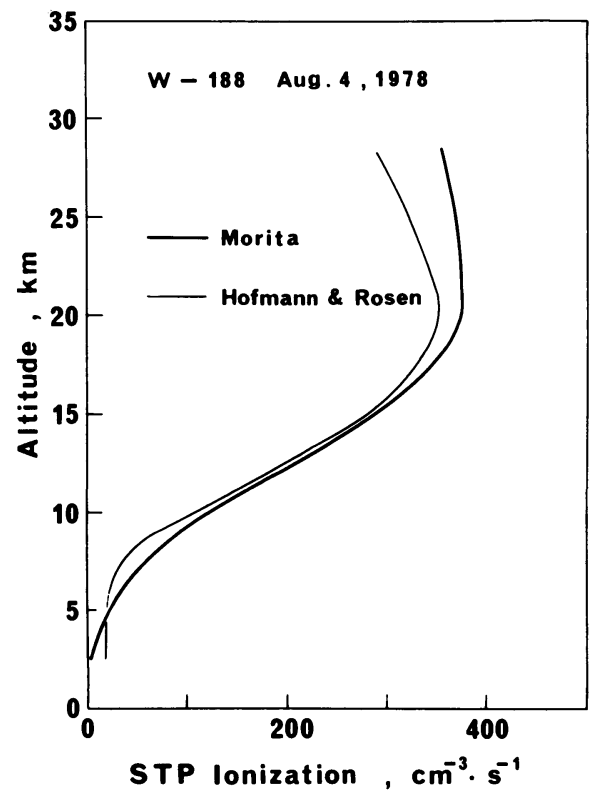

Fig. 2. A comparison of STP ion pair production rate profiles over Laramie, Wyoming on Aug. 4, 1978.

definitive conclusions can be reached regarding the disagreement at the stratospheric heights at the present time. The question will be resolved by further comparison measurements.

\subsection{Dependence of ion pair production rate on solar activity}

Cosmic rays are the main source of ion pair production in the stratosphere and the ion pair production rate thus depends on the geomagnetic latitude and solar activity. NeHER $(1967,1971)$ gave the latitude variation of ion pair production rate and the inverse correlation between ion pair production rate and solar sunspot cycle from his comprehensive research. The present results also show a marked dependence of ion pair production rate on solar activity. Figure 3 shows the results of ion pair production measurements of Nagoya University. The agreement of the two profiles of W-183 and 188 is reasonably good. To see the influence of solar activity on the ion pair production rate in the stratosphere, additional profiles obtained from other separate soundings are compared in Fig. 3. The profiles were obtained on Dec. 19, 1979 (W-220) and on June 27, 1980 (W-239) over Laramie, Wyoming ( $+50^{\circ}$ geomag. lat.). Above $15 \mathrm{~km}$ the difference between the profiles of W-183, 188 and W-220, 239 is quite evident. Solar Geophysical Data give the Zülich smoothed sunspot numbers shown in Fig. 4 for Solar Cycle 21 beginning in June 1976. The periods of ion pair production rate measurements are shown by arrows in Fig. 4. The variation of observed sunspot numbers suggests the maximum occured in the interval December 1979-January 1980 and the period 


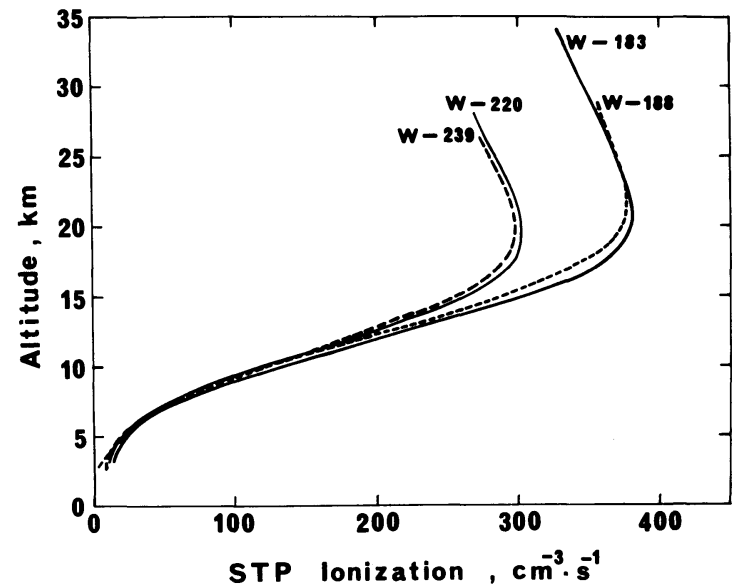

Fig. 3. A comparison of STP ion pair production rate profiles measured at the times of different sunspot numbers.

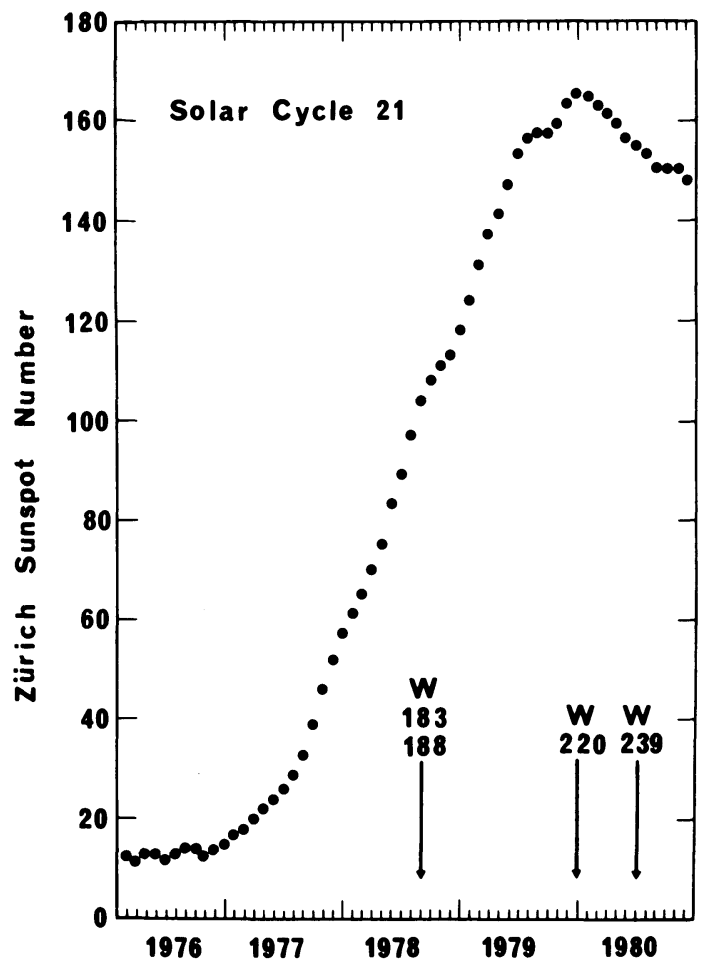

Fig. 4. Solar sunspot number versus time during ion pair production rate measurements. 
coincides with that of the measurements of W-220. Thus the present measurements of ion pair production rate are consistent with the inverse correlation between solar activity and galactic cosmic radiation flux.

\subsection{Ion-ion recombination coefficient}

If both values of ion pair production rate and small ion density are obtained by making the simultaneous measurements at the same location, the effective ion-ion recombination coefficient can be calculated. It is also possible to calculate the recombination coefficient by using electrical conductivity instead of small ion density provided the reduced ion mobility retains a constant value up to the stratospheric heights. Two simultaneous measurements of ion pair production rate and positive polar conductivity were carried out during the workshop.

Assuming a simple theory of small ion equilibrium under steady state conditions in the aerosol-free atmosphere, the effective ion-ion recombination coefficient $\alpha$ is given by the well known equation $\alpha=q / n^{2}$, where $q$ and $n$ are the ambient ion pair production rate and the small ion density, respectively. The values of ambient ion pair production rate converted from the average value of STP ion pair production rate of W-183 and 188 in Fig. 3 are used as $q$ in the present calculation. The profiles of positive polar conductivity for the flights of W-183 and 186 are shown in Fig. 5, where the continuous line is the average profile of the two flights. The agreement of the two profiles is quite good and an excellent agreement is obtained above $20 \mathrm{~km}$. The small ion density $n$ was calculated from the average conductivity profile shown in Fig. 5.

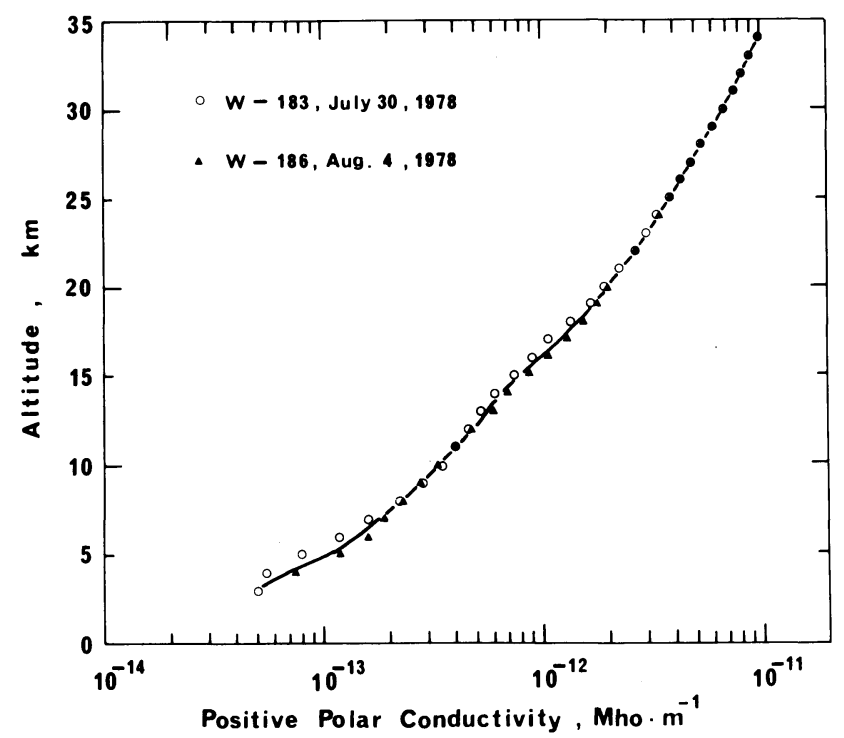

Fig. 5. Positive polar conductivity profiles over Laramie, Wyoming. 
The average mobility of small ions is inversely proportional to atmospheric density. Usually the value lies between $(1.0-2.0) \times 10^{-4} \mathrm{~m}^{2} / \mathrm{V} \mathrm{sec}$ at ground level and increases by a factor of about 100 at an altitude of $30 \mathrm{~km}$. The ionic mobilities of positive ions in the stratosphere have been measured by several investigators. There was, however, considerable disagreement between the results reported by the investigators and the mobility measurements differ by more than an order of magnitude at a $30 \mathrm{~km}$ altitude (e.g., MEYEROTT et al., 1980). This is probably due to the difficulty of ion mobility measurement in the stratosphere. Though considerable different values of ion mobility have been obtained in the stratosphere, the mobility of $1.3 \times 10^{-4}$ $\mathrm{m}^{2} / \mathrm{V}$ sec reduced to STP is assumed in this study. This assumption is supported by the measurements of MoRITA et al. (1971) and RosEN et al. (1982). Morita et al. obtained the constant reduced ion mobility of $1.3 \times 10^{-4} \mathrm{~m}^{2} / \mathrm{V} \mathrm{sec}$ from the balloon-borne simultaneous measurements of electrical conductivity and small ion density. Recent measurements of Rosen et al. indicate that the values of reduced positive ion mobility are relatively constant with altitude to about $30 \mathrm{~km}$.

The small ion density $n$ and the ambient ion pair production rate $q$ used in this calculation are shown in Fig. 6. Open circles in Fig. 6 represent the recombination coefficient $\alpha$ calculated using the two parameters. Also shown in Fig. 6 is the Thomson three-body recombination coefficient $\left(\alpha_{3 b}\right)$ as described by LOEB (1955). As the three-

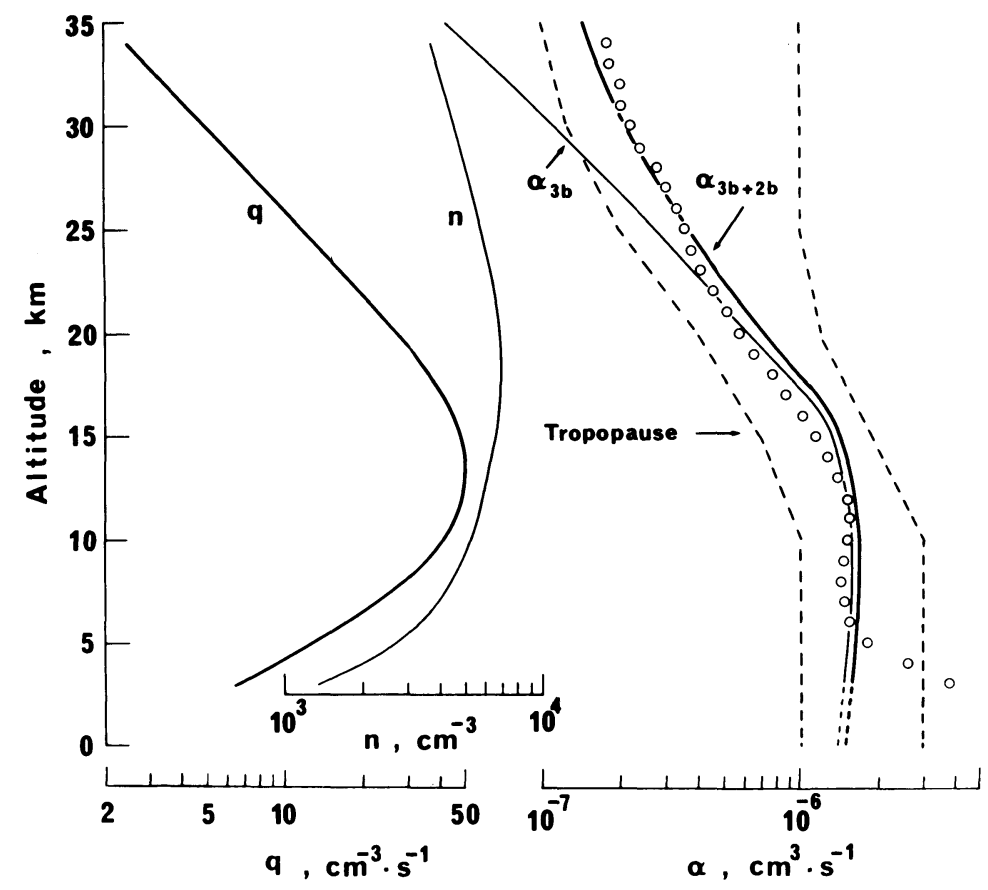

Fig. 6. A comparison of recombination coefficient $(\alpha)$ profiles. Ambient ion pair production rate $(q)$ and small ion density $(n)$ profiles used in the present calculation are also shown. See text for details. 
body recombination coefficient depends on temperature, the mean temperature profile of these flights was used in the calculation. The three-body recombination coefficient is shown by normalizing the value at the ground level to $1.4 \times 10^{-6} \mathrm{~cm}^{3} / \mathrm{sec}$ obtained from the experimental measurements of NolAN (1943). This surface value is thought to be the most reliable by several investigators (e.g., HopPEL, 1969). The three-body recombination theory has been refined and developed by several workers (NATANSON, 1959; BRICARD, 1965; HOPPEL, 1969; and others). They are not mutually in entire agreement but do not show serious significant differences.

At higher altitudes the recombination process is thought to be controlled by a two-body reaction. The two-body recombination coefficient is independent of pressure but depends on temperature. The range of experimental values of the three-body coefficient at the ground level is approximately 1 to $2 \times 10^{-6} \mathrm{~cm}^{3} / \mathrm{sec}$, while the range of the two-body coefficient lies between $10^{-6}$ and $10^{-7} \mathrm{~cm}^{3} / \mathrm{sec}$ (HAKE et al., 1973). The combined three- and two-body recombination coefficient $\left(\alpha_{3 b+2 b}\right)$ is shown in Fig. 6 , in the case that the value of $1.0 \times 10^{-7} \mathrm{~cm}^{3} / \mathrm{sec}$ at $280^{\circ} \mathrm{K}$ is chosen as the two-body recombination coefficient. The three-body recombination coefficient in Fig. 6 decreases more rapidly than the combined recombination coefficient with increasing altitude above the tropopause. The present experimental values of the recombination coefficient (open circles) follow the three-body coefficient in the altitude range between 6 and $20 \mathrm{~km}$, and they are fit for the combined coefficient above $25 \mathrm{~km}$. This suggests that the "crossover" from three-body to two-body recombination starts from above $23 \mathrm{~km}$. HAKE et al. (1973) constructed plausible upper and lower limits for the profile of the combined recombination coefficient based on the estimates of several investigators (e.g., Cole and Pierce, 1965; Shreve, 1970; and others). The limits are also shown by broken lines in Fig. 6. The crossover from three-body to two-body in the estimation of Hake et al. is at $15 \mathrm{~km}$ on the upper limit and it is at $25 \mathrm{~km}$ for the lower limit. A recent measurement of GRINGEL et al. (1978) indicated that the crossover began at an altitude around $20 \mathrm{~km}$. Thus the height variation of the present experimental ion-ion recombination coefficient above $6 \mathrm{~km}$ is reasonable.

However, below $5 \mathrm{~km}$ the disagreement with the theoretical concepts is quite evident. The calculation reported here does not include the influence of aerosol on the small ion density. The apparent large values of the recombination coefficient could be attributed to the attachment of ions to aerosols in the lower troposphere. At this time of the measurements, the stratospheric aerosol concentration was on a background level (Hofmann and Rosen, 1981) and the attachment loss of small ions to aerosols in the stratosphere was negligible compared with ion-ion recombination.

The three-body recombination coefficient depends on ionic mass. The ionic mass in the troposphere and lower stratosphere is not yet precisely known. Recent mass spectrometric measurements in the stratosphere indicate the existence of two major positive and negative ion species (ARIJS et al., 1981; ARNOLD et al., 1981; HENSCHEN and ARNOLD, 1981; and others). The positive ions are thought to be proton hydrates, $\mathrm{H}^{+}\left(\mathrm{H}_{2} \mathrm{O}\right)_{n}$, and non-proton hydrates, $\mathrm{HX}_{l}^{+}\left(\mathrm{H}_{2} \mathrm{O}\right)_{m}$. The negative ions in the stratosphere are now believed to be $\mathrm{NO}_{3}^{-}\left(\mathrm{HNO}_{3}\right)_{n}$ and $\mathrm{HSO}_{4}^{-}\left(\mathrm{H}_{2} \mathrm{SO}_{4}\right)_{l}\left(\mathrm{HNO}_{3}\right)_{m}$. It is expected that more complex ions exist in the troposphere and lower stratosphere. Two- 
body recombination process also depends on the ionic composition. The values of the rate coefficient for two-body recombination measured by Moseley et al. (1972) are $(1-5) \times 10^{-7} \mathrm{~cm}^{3} / \mathrm{sec}$ for unclustered positive and negative ions. Recent laboratory experiment made by SMITH et al. (1981) shows that the values are (5-7) $\times 10^{-8} \mathrm{~cm}^{3} / \mathrm{sec}$ for the reaction of $\mathrm{H}^{+}\left(\mathrm{H}_{2} \mathrm{O}\right)_{4}$ and $\mathrm{H}^{+}\left(\mathrm{H}_{2} \mathrm{O}\right)\left(\mathrm{CH}_{3} \mathrm{CN}\right)_{3}$ with several negative ion species observed in the stratosphere. Laboratory experiments, however, have not been carried out for all ion species existing in the stratosphere. Our present knowledge in this regard is limited for troposphere and lower stratosphere, and the details have not been worked out. It is thus necessary to determine the height variation of the "effective ionion recombination coefficient" from the reliable experimental measurements of atmospheric electrical elements as mentioned above.

I wish to express my sincere thanks to Professors D.J. Hofmann and J. M. Rosen of Department of Physics and Astronomy, the University of Wyoming for providing me with the opportunity to carry out the balloon flights in Laramie, Wyoming. I am also indebted to Professor T. Ogawa of Geophysical Institute, Kyoto University and to Professor M. Takagi of Research Institute of Atmospherics, Nagoya University for their discussions. The workshop received partial support from the Office of Naval Research, the National Science Foundation, the Department of Transportation, and the Army Research Office.

\section{REFERENCES}

ANDERSON, H. R., Cosmic ray total ionization, 1970-1972, J. Geophys. Res., 78, 3958-3960, 1973.

Aris, E., D. D. Nevejans, P. Frederick, and J. INGels, Negative ion composition measurements in the stratosphere, Geophys. Res. Lett., 8, 121-124, 1981.

ARnold, F., R. FAbian, E. E. Ferguson, and W. Joos, Mass spectrometric measurements of fractional ion abundances in the stratosphere-negative ions, Planet. Space Sci., 29, 195-203, 1981.

BRICARD, J., Action of radioactivity and of pollution upon parameters of atmospheric electricity, in Problems of Atoms. Space Electr., edited by S. C. Coroniti, pp. 82-117, Elsevier Publishing Co., Amsterdam, 1965.

COLE, R.K.Jr. and E.T.PIERCE, Electrification in the earth's atmosphere for altitudes between 0 and $100 \mathrm{~km}, J$. Geophys. Res., 70, 2735-2749, 1965.

Gringel, W., K. H. KäSELAU, and R. MüHLEISEN, Recombination rates of small ions and their attachment to aerosol particles, Pageoph., 116, 1101-1113, 1978

HaKe, R. D. Jr., E. T. PierCe, and W. VIEZeE, Stratospheric electricity, Final report, SRI Project 1724, 140, Stanford Res. Inst., Menlo Park, Calif., 1973.

HensChen, G. and F. ARNOLD, Extended positive ion composition measurements in the stratosphereImplications for neutral trace gasses, Geophys. Res. Lett., 8, 999-1001, 1981.

Hofmann, D. J. and J. M. Rosen, Measurements of ion production rate in the atmosphere, Univ. of Wyoming, Atmospheric Physics Report No. AP-54, 1979.

Hofmann, D. J. and J. M. Rosen, On the background stratospheric aerosol layer, J. Atmos. Sci., 38, 168-181, 1981.

HoPPEL, W. A., Application of three-body recombination and attachment coefficients to tropospheric ions, Pageoph., 75, 158-166, 1969.

IKEBE, Y., Evaluation of the total ionization in the lower atmosphere, J. Earth Sci. Nagoya Univ., 18, 85-121, 1970.

LoEB, L. B., Basic Processes of Gaseous Electronics, pp. 545, Univ. Calif. Press., 1955. 
Meyerott, R. E., J. B. Reagan, and R. G. JoIner, The mobility and concentration of ions and the ionic conductivity in the lower stratosphere, J. Geophys. Res., 85, 1273-1278, 1980.

Morita, Y., H. Ishikawa, and M. Kanada, The vertical profiles of the small ion density and the electric conductivity in the atmosphere in 19 kilometers, J. Geophys. Res., 76, 3431-3436, 1971.

MoRITA, Y. and H. IsHIKAWA, Simultaneous measurements of electric conductivity and aerosol in the lower stratosphere, J. Geomag. Geoelectr., 28, 309-315, 1976.

Morita, Y., H. IshiKaWA, and M. TAKAGI, On the recent measurements of the electrical parameters and aerosols in the lower stratosphere, Bull. Inst. Space Aeron., Univ. Tokyo, 15, 255-267, 1979 (in Japanese).

Moseley, J. T., W. Aberth, and R. Peterson, Two-body mutual neutralization rates of $\mathrm{O}_{2}^{+}+\mathrm{O}^{-}, \mathrm{NO}^{+}$ $+\mathrm{O}^{-}$, and $\mathrm{Na}^{+}+\mathrm{O}^{-}$obtained with mearged beams, J. Geophys. Res., 77, 255-259, 1972.

Natanson, G. L., The theory of volume recombination of ions, Soviet Phys., Tech. Phys., 4, 1263-1269, 1959 (Engl. translation).

NEHER, H. V., Cosmic ray particles that changed from 1954 to 1958 to 1965 , J. Geophys. Res., 72, 1527-1539, 1967.

NEHER, H. V., Cosmic rays at high latitudes and altitudes covering four solar maxima, J. Geophys. Res., 76, 1637-1651, 1971.

Nolan, P. J., The recombination law for weak ionization, Proc. Roy. Irish Acad., 49A, 67-90, 1943.

OGawA, T., Analyses of measurement techniques of electric fields and currents in the atmosphere, Contrib. Geophys. Instit., Kyoto Univ., 13, 111-137, 1973.

Rosen, J. M., D. J. Hofmann, W. Gringel, J. Berlinski, S. Michinowski, Y. Morita, T. Ogawa, and D. OLsON, Results of an international workshop on atmospheric electrical measurements, J. Geophys. Res., 87, 1219-1227, 1982.

SHREVE, E. L., Theoretical derivation of atmospheric ion concentrations, conductivity, space charge density, electric field and generation rate from 0 to $60 \mathrm{~km}$, J. Atmos. Sci., 27, 1186-1194, 1970.

Smith, D., N. G. ADAmS, and E. AlgE, Ion-ion mutual neutralization and ion-neutral switching reactions of some stratospheric ions, Planet. Space Sci., 29, 449-454, 1981. 